\title{
What do US and Canadian parents do to encourage or discourage physical activity among their 5-12 Year old children?
}

\author{
Andrew W. Tu', Teresia M. O'Connor ${ }^{2}$, Mark R. Beauchamp ${ }^{3}$, Sheryl O. Hughes², Tom Baranowski ${ }^{2}$
} and Louise C. Mâsse 1* $^{*}$

\begin{abstract}
Background: Parents have the potential to substantively influence their child's physical activity. This study identified the parenting practices of US and Canadian parents to encourage or discourage their 5-12 year-old child's physical activity and to examine differences in parenting practices by country, parental sex, age of child, and income.

Methods: The sample consisted of 134 US and Canadian parents (54.5\% US; 60.4\% female) recruited from a web-based panel by a polling firm. The parents answered open-ended questions about what they and other parents do to encourage or discourage their child to be active. Responses were coded using a scheme previously developed to code items used in the published literature. Coded responses were summarized by domain and dimension with differences in responses by country, parental sex, age of child, or household income assessed with a log-linear analysis.

Results: The 134 parents provided 649 and 397 responses to ways that parents encourage or discourage their child's physical activity, respectively. Over $70 \%$ of responses for practices that encourage physical activity were related to structure of the environment, parental encouragement, and co-participation. The most common response was coparticipation in activity with the child. Of the practices that discourage physical activity, $67 \%$ were related to structure of the environment, lack of parental control, and modeling poor behaviors. The most common response was allowing screen time. There were no differences in response by country, parental sex, child age, or household income.

Conclusions: Parents most often encouraged physical activity through structure and emotional support and discouraged physical activity through lack of structure and control. Understanding how parents influence their child's physical activity may help improve intervention strategies. The current results will inform the development of a physical activity parenting practices instrument.
\end{abstract}

Keywords: Parenting, Parenting practices, Physical activity, Child, Qualitative

\section{Background}

High levels of physical activity during childhood have been linked to a number of health benefits including a reduction in blood pressure, blood lipid levels, body fat, and depressive symptoms and an improvement in bone density [1]. Despite these benefits, national physical activity levels are low. Recent estimates have found that less than $20 \%$ of Canadian and US children between the

\footnotetext{
* Correspondence: Lmasse@bcchr.ubc.ca

${ }^{1}$ Child \& Family Research Institute, School of Population and Public Health, University of British Columbia, Vancouver, BC, Canada

Full list of author information is available at the end of the article
}

ages of 6 and 19 accumulate at least 60 min of physical activity per day [2, 3].

Parents have been identified as having the potential to substantively influence their child's physical activity $[4,5]$. For example, parents can provide emotional (e.g., praise, encouragement) or tangible (e.g., financial, transportation) support for physical activity; directly model physical activity; structure their child's environment to promote physical activity; promote autonomous decision making regarding physical activity; or attempt to control their child's behavior (e.g., through pressure or restriction) [6]. These parenting behaviors or practices were related to child physical activity levels, although the evidence was 
weak and mixed [7-9]. A systematic review of physical activity parenting practice studies revealed that parental support for physical activity was most consistently associated with child physical activity; however, support typically encompassed multiple domains (e.g., encouragement, co-participation, tangible support) [9]. In a longitudinal study, parental encouragement to be physically active was associated with children's levels of physical activity 5 years later [10].

Few studies have qualitatively examined the parenting practices that parents commonly use to encourage or discourage their child to be physically active. Existing qualitative studies focused on specific ethnic populations [11-13]. Nominal group technique sessions were conducted with Chinese [11] and Hispanic [12] parents of preschoolers and found that parents most often reported parental engagement, logistic support, parental encouragement, and promoting other health behaviors as practices used to encourage physical activity and safety concerns, permissiveness of sedentary behavior, lack of time, psychological control, and emotional abuse as practices used to discourage physical activity. Among Australian Middle Eastern parents of 5 to 12 year old children, the majority of parents promoted physical activity through organized sports and encouraging outdoor play while focus on academic achievement and lack of time were reasons parents discouraged physical activity [13]. Therefore, there is need to gain a greater understanding in more diverse samples. Assessing the physical activity parenting practices among samples representative of the general US and Canadian populations can inform development of a parenting practice measure to fully understand how parenting affects health behaviors.

Building from our previous study which found that parents reported using physical activity parenting practices that are not included in current measures [6], this study qualitatively explored the parenting practices that may encourage or discourage physical activity in their children. This disconnect between parent reported practices and practices measured in the literature highlights the importance of collecting qualitative data to understand how parents influence their child's behavior. The objective of this study was to identify the parenting practices that are predominantly reported by US and Canadian parents to encourage or discourage their child's physical activity. In addition, this paper explored whether the parenting practices differed by: 1) parental sex and age of child as previous studies found differences in physical activity parenting practices for both of these indicators [9]; 2) income as this variable is a marker of resources which can be devoted to physical activity; and 3) country as it was thought important to examine the stability of the findings across the sample. This study opted to use income instead of educational background since educational background of both parents was not collected.

\section{Methods}

This research protocol was approved by the Research Ethics Board of the University of British Columbia and received Institutional Review Board approval from the Baylor College of Medicine.

\section{Sample}

The sample consisted of parents of 5-12 year old children who were living in Canada or the USA. Parents were recruited by an internet research polling firm (YouGovPolimetrix, US) from their web-based panel membership. Recruitment from a polling firm represented a cost-effective approach of obtaining a large representative sample over other sampling approaches. Recruitment occurred between November 2013 and February 2014. All panel members provided consent to be part of the panel and to participate in the survey. To be eligible, participants had to be the primary guardian of a 5 to 12 year old child. Participants were excluded if the child had a physical or learning disability that limited their child's physically activity. Panel members were sampled to reflect the socio-economic and ethnic diversity of the two countries based on the 2012 US and 2011 Canadian census estimates. To reflect socio-economic diversity, country-specific household income cut-points $(<40$ th percentile, $\geq 40$ th to $\leq 80$ th percentile, and $>80$ th percentile) were created and a corresponding percentage of participants $(40 \%$; $40 \%$; $20 \%)$ were recruited into each group. To reflect ethnic diversity, participants were recruited based on the percentages of the largest ethnic groups for each country (White, Hispanic, Black, and other in the US and White, East/Southeast Asian, South/West Asian, and other in Canada). In addition, the sample was balanced between parents with younger (5-8 years of age) and older (9-12 years of age) children. In total, 134 parents (73 US and 61 Canadian) provided valid responses. Participants received 2000 points for their participation in this survey which could be redeemed as cash or gift cards valued at about \$5 USD/Cdn.

\section{Questionnaire}

Parents were asked to respond to a series of screening and socio-demographic questions to ensure eligibility. Those who met the eligibility criteria were asked to respond to the following four questions based on their youngest or oldest child within the age criteria (selected by the data collection program): 1) What sorts of things do you do to encourage your child to be physically active?; 2) What rules or guidelines do you have that may encourage your child to be physically active?; 3 ) What sorts of things might you do that may unintentionally 
affect your child from being physically active?; 4) Thinking about other parents with children of the same age, what things do they do that may discourage their children from being physically active? The fourth question asked parents to respond generally about other parents to avoid socially desirable responses. Each of the four questions was openended and parents could provide up to ten 160 character responses per question. A character limit was set to limit each response to one practice and to encourage parents to provide multiple responses (i.e., identify several parenting practices). Parents were prompted to expand on their responses if they provided short answers ( $<50$ characters). As the questions were open-ended, parents were blocked from completing the questionnaire on their mobile devices which may limit their ability to type more detailed responses. The online survey was piloted among 25 Canadian parents using cognitive interviewing techniques [14]. Responses from questions 1 and 2 were grouped and categorized as encouraging parenting practices and responses from questions 3 and 4 were grouped and categorized as discouraging parenting practices.

\section{Coding of responses}

Detailed information about the development of the coding scheme used in this study can be found elsewhere [6]. Briefly, the coding scheme was initially developed to code 74 published questionnaires/instruments designed to assess physical activity parenting practices, which included 608 items [6]. The coding scheme was developed based on a review of these published constructs, associated items and was informed by conceptual frameworks of parenting practices for physical activity and nutrition $[15,16]$. The coding scheme consisted of 6 broad domains, 14 dimensions, and 1 to 5 sub-dimensions [6]. The domains (dimensions in parenthesis) were structuring of the activity environment (monitoring, structure of the environment); emotional support (expressing positive emotions, parental encouragement); parental control (expressing negative emotions, lack of parental control, pressure to be active, restriction, rewards and discipline); informational support (modeling, teach/reason); autonomy promotion (autonomy support, co-participation); and tangible support (logistic support/facilitation) (see our previous study for the full coding scheme and detailed definitions) [6]. Each item from the 74 instruments was assigned to a dimension and sub-dimension in order to group similar items. The list of items was further reduced using a winnowing process that grouped similar items into a statement that best captured the parenting practice (608 items winnowed to 100 parenting practice statements). For example, three published items asking about parent co-participation in physical activity ("During a typical week, how often has a female adult done physical activity with you?"; "How often do you exercise with one or both of your parents?"; and "How often do you do the following activities together as a family with at least one adult family member - Play sports?") were reduced to the following generic statement "Participate in [physical activity, sports, exercise] or play active games with my child."

Each parent response to the four questions on the online questionnaire was coded to a parenting practice from the consolidated list of 100 parenting practice statements. For example, when parents were asked what they did to encourage their child to be physically active, one parent responded "Ask if she wants to join sports at school, usually she does not" which was coded to the item "I allow my child to choose whether s/he participates in sports or vigorous physical activity in his/her free time." As the item was meant to describe a concept, responses in a negative direction could have been coded to an item in the opposite direction, if that already existed in the coding scheme. For example, one parent's response to a question asking what the other parents did to discourage their child from being physically active responded "Not participating with their kids at all" which was coded to the item "I participate in [activity type] with my child." If the parent response had elements of two distinct items, then the response was coded to both items. Coding was conducted independently by two researchers, discrepancies were discussed, and a consensus was reached. A third researcher reviewed the coding and discussed discrepancies with the other two researchers. A new code was created for any unique parenting item that did not appear in the literature. If more than one response from the same parent was coded to the same item, the additional responses were removed to avoid repetition.

\section{Analysis}

Coded responses to the encouraging and discouraging questions were ranked by domain and dimension. To assess whether there were differences in responses by country, parental sex, age of child, or household income, a log-linear analysis with iterative proportional fitting was conducted. Log-linear analysis is an iterative process which can test for higher order (e.g., three-way) associations among categorical variables. Analyses were conducted on the above four sets of variables with each set including the coded domain (6 categories), a dichotomous variable indicating whether the response was encouraging or discouraging ( 2 categories), and one of country (USA, Canada), parental sex (male, female), age of child (5-8, 9-12), or household income (below median, above median). All two- and three-way interactions were assessed within each set. For each set, a saturated model was formed and each higher order term was sequentially removed to examine the goodness-of-fit. Model 
fit was based on Pearson's Chi-square statistic $\left(x^{2}\right)$ and the deviance statistic $\left(G^{2}\right)$. Models with significant goodness-of-fit statistics suggest poor fit. The most parsimonious model (model with least number of interaction terms) was chosen as the best fitting model for each set. A $p$-value of $<0.05$ was considered significant. Stata (version 13.1, College Station, Texas) was used for all analyses.

\section{Results}

Participant characteristics can be found in Table 1. Of the 134 participants, 73 (54.5\%) were from the US and 81 (60.4\%) were female. On average, each parent provided 4.8 (SD 2.5; range 0-13) responses to practices that encourage physical activity and 3.0 (SD 1.9; range 0-11) responses to practices that discourage physical activity. In total, from the 134 parents, 649 responses were practices that parents said encouraged their child to engage in physical activity (coded to 78 unique parenting practices) and 397 responses were practices that discouraged physical activity (coded to 69 unique parenting practices). In addition, 27 of the parenting practices (17 encouraging and 10 discouraging practices) did not link to any of the 100 parenting practices statements found in the published measures of physical activity parenting (see Additional file 1: Appendices 1 and 2 for parenting practices not included in the literature).

Table 1 Participant characteristics

\begin{tabular}{lll}
\hline & USA $(n=73)$ & Canada $(n=61)$ \\
\hline Parent Sex (female) & $43(58.9)$ & $38(62.3)$ \\
Age of child & & \\
$5-8$ & $33(45.2)$ & $32(52.5)$ \\
$9-12$ & $40(54.8)$ & $29(47.5)$ \\
Marital status & & \\
Married or common-law & $54(74.0)$ & $50(82.0)$ \\
Separated or divorced & $11(15.1)$ & $8(13.1)$ \\
Never married & $7(9.6)$ & $3(4.9)$ \\
Widowed & $1(1.4)$ & 0 \\
Education & & $5(8.2)$ \\
High school or less & $22(30.1)$ & $16(26.2)$ \\
Certificate/diploma/or some & $13(17.8)$ & $29(47.5)$ \\
college or university education & & $11(18.0)$ \\
Bachelor's degree & $22(30.1)$ & \\
Postgraduate degree & $16(21.9)$ & $35(57.4)$ \\
Income & & $26(42.6)$ \\
Below median & $37(50.7)$ & 0 \\
Above median & $32(43.8)$ & $4(5.5)$ \\
Missing & & \\
\hline
\end{tabular}

\section{Parenting practices that encourage physical activity}

About two-thirds of the responses to ways parents encouraged physical activity were coded to structure of the activity environment and emotional support (see Table 2). The ten most coded responses are displayed in Table 3 and represent 50\% of all responses related to encouraging physical activity. The full list of coded responses can be found in Additional file 1: Appendix 1. The percentage of participants that mentioned each of the top 10 parenting practices ranged from $15.7 \%$ to $33.6 \%$. The top 10 practices used to encourage physical activity included co-participation (participating in physical activity or walks with child), parental encouragement (encouraging outdoor play, physical activity, biking or walking in the neighborhood), structure of the environment (restricting sedentary behavior, ensuring active transport, taking child to park or play spaces), and tangible support (enrolling child in physical activity).

\section{Parenting practices that discourage physical activity}

About two-thirds of responses to ways parents discourage physical activity were coded to the structure of the activity environment and parental control domains with structure, lack of parental control, and restriction being the dominant dimensions (Table 2). The top 10 most coded responses are displayed in Table 4 and make up $60 \%$ of all responses to parenting practices that discourage

Table 2 Responses by domain and dimension

\begin{tabular}{lll}
\hline & $\begin{array}{l}\text { Encourage } \\
(\mathrm{n}=649)\end{array}$ & $\begin{array}{l}\text { Discourage } \\
(\mathrm{n}=397)\end{array}$ \\
\hline Structure of the activity environment & $236(36.4)$ & $154(38.8)$ \\
Monitoring & $15(2.3)$ & $1(0.3)$ \\
Structure of the environment & $221(34.1)$ & $153(38.5)$ \\
Emotional support & $183(28.2)$ & $15(3.8)$ \\
Expressing positive emotions & $8(1.2)$ & $5(1.3)$ \\
Parental Encouragement & $175(27.0)$ & $10(2.5)$ \\
Parental control & $32(4.9)$ & $113(28.5)$ \\
Lack of parental control & $2(0.3)$ & $65(16.4)$ \\
Expressing negative emotions & $6(0.9)$ & $8(2.0)$ \\
Pressure to be active & $11(1.7)$ & $2(0.5)$ \\
Restriction & $1(0.2)$ & $34(8.6)$ \\
Rewards and discipline & $12(1.9)$ & $4(1.0)$ \\
Informational support & $50(7.7)$ & $50(12.6)$ \\
Modeling & $21(3.2)$ & $49(12.3)$ \\
Teach/reason & $29(4.5)$ & $1(0.3)$ \\
Autonomy promotion & $84(12.9)$ & $19(4.8)$ \\
Autonomy support & $(1.2)$ & $(11.7)$ \\
Cangible support & $64(9.9)$ & $16)$ \\
\hline
\end{tabular}


Table 3 Top 10 coded responses to parenting practices that encourage physical activity $(n=649)$

\begin{tabular}{|c|c|c|c|c|c|c|}
\hline Coded Response & Domain & Dimension & $\begin{array}{l}\text { Number of } \\
\text { responses }\end{array}$ & $\begin{array}{l}\text { Percent of } \\
\text { responses }\end{array}$ & $\begin{array}{l}\text { Percent of } \\
\text { participants }\end{array}$ & Sample parent responses \\
\hline $\begin{array}{l}\text { I participate in [activity type] or play } \\
\text { active games with my child. }\end{array}$ & $\begin{array}{l}\text { Autonomy } \\
\text { Promotion }\end{array}$ & Co-participation & 45 & 6.9 & 33.6 & $\begin{array}{l}\text { "We ride bike every afternoon" } \\
\text { "When it is warm, we play tag } \\
\text { outside" } \\
\text { "We will wrestle around the house" }\end{array}$ \\
\hline $\begin{array}{l}\text { When the weather is nice, I encourage } \\
\text { my child to play outside. }\end{array}$ & $\begin{array}{l}\text { Emotional } \\
\text { Support }\end{array}$ & $\begin{array}{l}\text { Parental } \\
\text { Encouragement }\end{array}$ & 40 & 6.2 & 29.9 & $\begin{array}{l}\text { "Weather permitting, put them } \\
\text { outside in the yard for set periods } \\
\text { of time" } \\
\text { "We encourage her to go outside" } \\
\text { "I encourage her to invite her friends } \\
\text { over to play outside or go to the park" }\end{array}$ \\
\hline $\begin{array}{l}\text { I limit the amount of time my child } \\
\text { spends [sedentary activity type] on } \\
\text { weekend/weekday. }\end{array}$ & $\begin{array}{l}\text { Structure of } \\
\text { the Activity } \\
\text { Environment }\end{array}$ & $\begin{array}{l}\text { Structure of the } \\
\text { Environment }\end{array}$ & 39 & 6.0 & 29.1 & $\begin{array}{l}\text { "We limit her computer and TV time" } \\
\text { "Cut back video games to only } \\
\text { weekends" } \\
\text { "They only have } 2 \mathrm{~h} \text { a day of video } \\
\text { games, the rest either outside or } \\
\text { reading" }\end{array}$ \\
\hline
\end{tabular}

$\begin{array}{llllll}\text { I enroll my child in [activity type]. } & \begin{array}{llll}\text { Tangible } \\ \text { Support }\end{array} & \begin{array}{l}\text { Logistic } \\ \text { Support/ }\end{array} & 37 & 5.7 & 27.6 \\ & & \text { Facilitation } & & \end{array}$

I encourage my child to participate in physical activity, or play sports (/in his/her free time).

I encourage my child to ride a bike and walk in our neighborhood to be active.

$\begin{array}{lllll}\text { Emotional } & \text { Parental } & 34 & 5.2 & 25.4\end{array}$

Support Encouragement

Emotional Support

Structure of the Activity Environment

\section{Structure of} the Activity Environment

Structure of Structure of the 24 the Activity Environment

Parental 33

Encouragement

Structure of the 27 Environment

Structure of the 26 Environment
Environment

transportation to do errands close home or to go places close to home such as by walking or bicycling.

I go for walks with my child.
Autonomy Promotion
Co-participation 21

3.2
"She is signed up in swimming and tennis classes"

"Sign him up to soccer, hockey, and basketball clubs to ensure that they get enough activity"

"Enroll him in a fitness program"

"Encourage him to participate in school sports"

"Play games with other siblings" "Encourage him to play at school playgrounds instead of staying inside the classes after lunch"

"They love riding bikes so I encourage that"

"Go for walks, walk the dog"

"Allow her to go outside to ride her bike and scooter"

"She walks to and from school with her brother"

"My kids walk to and from the bus stop every school day" "Walk to school when we can"

"I take her to the park to play" "I take him to the skating rink" "Go to the pool 3-4 times a week"

"We do light shopping on foot and heavy shopping by car"

"I encourage him to use a bicycle to go to close places"

"We walk to the library when the weather allows"

"She goes for walks with me" "Usually, we love to walk after meals" "Take them for walks with me every evening" physical activity (see Additional file 1: Appendix 2 for entire list). The most common practice reported was lack of parental control (allow child to watch TV or play video/ computer games whenever $\mathrm{s} / \mathrm{he}$ wants) which represented $15.9 \%$ of all responses to ways parents discourage physical activity and was mentioned by $47 \%$ of participants. The remaining parenting practices within the top 10 were mentioned by $7.5 \%$ to $20.1 \%$ of the participants. Coded responses in the top 10 included practices related to structure of the environment (requiring supervision when outdoors, restricting outdoor play, restricting physical activity indoors), restriction (due to potential injury), modeling (child sees me being sedentary), and tangible support (lack of time). 
Table 4 Top 10 coded responses to parenting practices that discourage physical activity $(n=397)$

\begin{tabular}{|c|c|c|c|c|c|c|}
\hline Coded Response & Domain & Dimension & $\begin{array}{l}\text { Number of } \\
\text { responses }\end{array}$ & $\begin{array}{l}\text { Percent of } \\
\text { responses }\end{array}$ & $\begin{array}{l}\text { Percent of } \\
\text { participants }\end{array}$ & Sample parent responses \\
\hline $\begin{array}{l}\text { allow my child to watch TV } \\
\text { or play video/computer games } \\
\text { whenever s/he wants to. }\end{array}$ & $\begin{array}{l}\text { Parental } \\
\text { Control }\end{array}$ & $\begin{array}{l}\text { Lack of parental } \\
\text { control }\end{array}$ & 63 & 15.9 & 47.0 & $\begin{array}{l}\text { "I let her watch more TV or use the } \\
\text { computer more than she should due } \\
\text { to other demands around the house" } \\
\text { "Letting their children rely on too many } \\
\text { electronic devices" } \\
\text { "Allow too much time on the computer } \\
\text { /TV" }\end{array}$ \\
\hline $\begin{array}{l}\text { My child must be supervised } \\
\text { when } s / \text { he is active outside. }\end{array}$ & $\begin{array}{l}\text { Structure of } \\
\text { the Activity } \\
\text { Environment }\end{array}$ & $\begin{array}{l}\text { Structure of the } \\
\text { Environment }\end{array}$ & 27 & 6.8 & 20.1 & $\begin{array}{l}\text { "I don't let her go outside alone" } \\
\text { "If I can't monitor you, you can't } \\
\text { participate in that" } \\
\text { "She does not ride her bike outside } \\
\text { alone except when an adult is with her" }\end{array}$ \\
\hline $\begin{array}{l}\text { I don't allow my child to play } \\
\text { outside in the street after dark } \\
\text { or after a certain time. }\end{array}$ & $\begin{array}{l}\text { Structure of } \\
\text { the Activity } \\
\text { Environment }\end{array}$ & $\begin{array}{l}\text { Structure of the } \\
\text { Environment }\end{array}$ & 26 & 6.5 & 19.4 & $\begin{array}{l}\text { "He is to come inside before it gets too } \\
\text { dark outside" } \\
\text { "Not allowing children out after dark" } \\
\text { "She can only play inside after dark" }\end{array}$ \\
\hline $\begin{array}{l}\text { My child sees me being } \\
\text { sedentary (e.g. watching } \\
\text { TV, on the computer, } \\
\text { sleeping a lot). }\end{array}$ & $\begin{array}{l}\text { Informational } \\
\text { Support }\end{array}$ & Modeling & 26 & 6.5 & 19.4 & $\begin{array}{l}\text { "We're both out of shape and watch } \\
\text { a lot of TV at night laying on the couch" } \\
\text { "I am on the computer often" } \\
\text { "Stay inside and do nothing ourselves" }\end{array}$ \\
\hline $\begin{array}{l}\text { I [am/have enough time } \\
\text { to be] involved in my child's } \\
\text { activities (e.g. coaching activities, } \\
\text { watching child play). }\end{array}$ & $\begin{array}{l}\text { Tangible } \\
\text { Support }\end{array}$ & $\begin{array}{l}\text { Logistic Support/ } \\
\text { Facilitation }\end{array}$ & 22 & 5.5 & 16.4 & $\begin{array}{l}\text { "Too tired/busy to play with them } \\
\text { outside" } \\
\text { "Not taking enough time or effort to } \\
\text { care for their children" } \\
\text { "Our lifestyle for now prevent him to be } \\
\text { more active" }\end{array}$ \\
\hline $\begin{array}{l}\text { I restrict some physical activities } \\
\text { because I am afraid my child will } \\
\text { be hurt. }\end{array}$ & $\begin{array}{l}\text { Parental } \\
\text { Control }\end{array}$ & Restriction & 20 & 5.0 & 14.9 & $\begin{array}{l}\text { "I don't let my child ride her scooter as } \\
\text { much as she would like because I am } \\
\text { scared she will get hurt" } \\
\text { "Bubble-wrapping them by not letting } \\
\text { them explore their environments" } \\
\text { "Discouraging him to run outside during } \\
\text { winter for fear of slipping and falling" }\end{array}$ \\
\hline $\begin{array}{l}\text { I don't allow my child to play } \\
\text { outside in bad weather. }\left(^{*}\right)\end{array}$ & $\begin{array}{l}\text { Structure of } \\
\text { the Activity } \\
\text { Environment }\end{array}$ & $\begin{array}{l}\text { Structure of the } \\
\text { Environment }\end{array}$ & 13 & 3.3 & 9.7 & $\begin{array}{l}\text { "If it is too cold, he is not allowed } \\
\text { outside" } \\
\text { "We don't allow our children to play in } \\
\text { the rain" } \\
\text { "I do not allow my child to play outside } \\
\text { when it is too cold/hot" }\end{array}$ \\
\hline $\begin{array}{l}\text { I restrict the amount of time my } \\
\text { child spends playing outside. }\end{array}$ & $\begin{array}{l}\text { Structure of } \\
\text { the Activity } \\
\text { Environment }\end{array}$ & $\begin{array}{l}\text { Structure of the } \\
\text { Environment }\end{array}$ & 12 & 3.0 & 9.0 & $\begin{array}{l}\text { "Not allow them to play outside with } \\
\text { other kids" } \\
\text { "He's always sick and I don't let him } \\
\text { outside" } \\
\text { "Keep them indoors versus taking them } \\
\text { outdoors" }\end{array}$ \\
\hline $\begin{array}{l}\text { I have rules that my child is not } \\
\text { allowed to walk [e.g., to the } \\
\text { neighborhood park] alone. }\end{array}$ & $\begin{array}{l}\text { Structure of } \\
\text { the Activity } \\
\text { Environment }\end{array}$ & $\begin{array}{l}\text { Structure of the } \\
\text { Environment }\end{array}$ & 10 & 2.5 & 7.5 & $\begin{array}{l}\text { "I won't let her walk alone" } \\
\text { "Do not allow him to go to the park on } \\
\text { his own" } \\
\text { "Don't let their kids walk anywhere on } \\
\text { their own" }\end{array}$ \\
\hline $\begin{array}{l}\text { I restrict [activity type] inside } \\
\text { the house. }\end{array}$ & $\begin{array}{l}\text { Structure of } \\
\text { the Activity } \\
\text { Environment }\end{array}$ & $\begin{array}{l}\text { Structure of the } \\
\text { Environment }\end{array}$ & 10 & 2.5 & 7.5 & $\begin{array}{l}\text { "I won't allow them to run in the house" } \\
\text { "Don't let them install chin-up bars in } \\
\text { the doorway" } \\
\text { "Stop them from playing when I am tired" }\end{array}$ \\
\hline
\end{tabular}

Log linear analyses were conducted to examine whether the responses differed by country, parental sex, age of child, and household income. Results of the loglinear analyses found that the best fitting model in all four cases was one that only included an interaction between dimension and encouraging/discouraging parenting practices (Table 5). Specifically, the interaction found that parents emphasized different dimensions depending on whether they wanted to encourage or discourage their child to be physically active. The lack of an 
Table 5 Results of the log linear analysis to test for differences in responses by parental sex, country, age of child, and household income

\begin{tabular}{|c|c|c|c|c|}
\hline & $G^{2}$ & $x^{2}$ & $d f$ & $p$-value \\
\hline \multicolumn{5}{|c|}{ Model 1: Parental sex } \\
\hline$(D, P, S)$ & 235.9 & 213.1 & 16 & $<0.001$ \\
\hline (D, PS) & 235.7 & 212.8 & 15 & $<0.001$ \\
\hline$(\mathrm{P}, \mathrm{DS})$ & 226.4 & 205.4 & 11 & $<0.001$ \\
\hline$(\mathrm{S}, \mathrm{DP})$ & 16.4 & 17.0 & 11 & 0.126 \\
\hline (DP, DS) & 6.86 & 6.92 & 6 & 0.334 \\
\hline$(\mathrm{DP}, \mathrm{PS})$ & 16.2 & 16.7 & 10 & 0.093 \\
\hline (DS, PS) & 226.2 & 205.0 & 10 & $<0.001$ \\
\hline (DP, DS, PS) & 6.59 & 6.70 & 5 & 0.253 \\
\hline (DPS) & 0 & 0 & 0 & \\
\hline \multicolumn{5}{|c|}{ Model 2: Country } \\
\hline$(D, P, C)$ & 228.7 & 209.4 & 16 & $<0.001$ \\
\hline$(\mathrm{D}, \mathrm{PC})$ & 228.7 & 209.4 & 15 & $<0.001$ \\
\hline$(P, D C)$ & 225.3 & 205.2 & 11 & $<0.001$ \\
\hline$(C, D P)$ & 9.22 & 9.22 & 11 & 0.601 \\
\hline$(\mathrm{DP}, \mathrm{DC})$ & 5.80 & 5.82 & 6 & 0.446 \\
\hline$(\mathrm{DP}, \mathrm{PC})$ & 9.17 & 9.17 & 10 & 0.516 \\
\hline$(\mathrm{DC}, \mathrm{PC})$ & 225.3 & 205.2 & 10 & $<0.001$ \\
\hline$(\mathrm{DP}, \mathrm{DC}, \mathrm{PC})$ & 5.79 & 5.81 & 5 & 0.327 \\
\hline$(\mathrm{DPC})$ & 0 & 0 & 0 & \\
\hline \multicolumn{5}{|c|}{ Model 3: Age of child } \\
\hline$(D, P, A)$ & 228.7 & 208.3 & 16 & $<0.001$ \\
\hline$(D, P A)$ & 228.7 & 208.3 & 15 & $<0.001$ \\
\hline$(P, D A)$ & 222.5 & 201.5 & 11 & $<0.001$ \\
\hline$(A, D P)$ & 9.20 & 9.12 & 11 & 0.604 \\
\hline$(\mathrm{DP}, \mathrm{DA})$ & 2.95 & 2.93 & 6 & 0.815 \\
\hline$(\mathrm{DP}, \mathrm{PA})$ & 9.19 & 9.12 & 10 & 0.514 \\
\hline$(\mathrm{DA}, \mathrm{PA})$ & 222.5 & 201.5 & 10 & $<0.001$ \\
\hline$(\mathrm{DP}, \mathrm{DA}, \mathrm{PA})$ & 2.81 & 2.78 & 5 & 0.729 \\
\hline (DPA) & 0 & 0 & 0 & \\
\hline \multicolumn{5}{|c|}{ Model 4: Household income } \\
\hline$(D, P, I)$ & 233.7 & 209.7 & 16 & $<0.001$ \\
\hline$(\mathrm{D}, \mathrm{PI})$ & 233.6 & 209.4 & 15 & $<0.001$ \\
\hline$(\mathrm{P}, \mathrm{DI})$ & 224.9 & 203.3 & 11 & $<0.001$ \\
\hline$(\mathrm{l}, \mathrm{DP})$ & 17.5 & 17.5 & 11 & 0.093 \\
\hline$(\mathrm{DP}, \mathrm{DI})$ & 8.75 & 8.70 & 6 & 0.188 \\
\hline$(\mathrm{DP}, \mathrm{Pl})$ & 17.5 & 17.5 & 10 & 0.065 \\
\hline$(\mathrm{DI}, \mathrm{Pl})$ & 224.8 & 203.2 & 10 & $<0.001$ \\
\hline$(\mathrm{DP}, \mathrm{DI}, \mathrm{PI})$ & 8.74 & 8.69 & 5 & 0.120 \\
\hline (DPI) & 0 & 0 & 0 & \\
\hline
\end{tabular}

$D$ Dimension (6 categories), $P$ Parenting behavior (Encourage/Discourage), $S$ Parental sex (M/F), C Country (USA/Canada), A Age of child (5-8/9-12), I Household income (below median/above median). XY represents two-way interactions; $\mathrm{XYZ}$ represents three-way interactions interaction with any of the socio-demographic variables indicates no differences were found in the responses by country, parental sex, age of child, or income.

\section{Discussion}

This study examined the parenting practices US and Canadian parents used to encourage and discourage physical activity. While the majority of the practices reported by the parents were captured in published research instruments, this study uncovered 27 unique parenting practices that were not captured (see Additional file 1: Appendix). This highlights the importance of conducting qualitative research in gaining a better understanding of parent's beliefs and health behaviors.

The most emphasized parenting practices used to encourage physical activity among children include coparticipation in physical activity, encouraging physical activity or outdoor play, limiting sedentary behavior, enrolling children in physical activity classes or lessons, ensuring children use active transportation to go places, and taking children to the park or play spaces. Similar to other studies, co-participation in physical activity was the most endorsed parenting practice used to encourage physical activity [11, 12]. Previous studies have found inconsistent associations between parent-child coparticipation in physical activity and child physical activity [17-19]; however, co-participation has also been included in a higher domain of parental support or encouragement which has been frequently associated with child physical activity [9]. The remaining parenting practices used to encourage physical activity were dominated by two domains: structure of the environment and parental encouragement. Structure refers to ways parents set up the environment in the home to influence their child's physical activity whereas parental encouragement refers to the various ways parents encourage children to participate in physical activity [6]. The frequency of reporting of these parenting practices suggests that parents may be more accepting to use these practices to encourage physical activity. Future interventions should explore whether promoting these practices will influence child physical activity behavior.

The most common parenting practices used by Canadian and US parents to discourage physical activity included allowing sedentary behavior, limiting outdoor time due to lack of supervision, darkness, or poor weather, modeling poor behaviors, lack of time, restricting physical activity due to injury, restricting the time spent outdoors, and restricting indoor physical activity. Similar to past studies, allowing sedentary behavior was the most endorsed practice to discourage physical activity $[11,12]$.. This practice was reported by almost half of the participants which was more than double the number of participants who reported the second-most endorsed practice used to discourage physical 
activity. Parental permissiveness of sedentary behaviors has been linked to increase screen time [20] but its association with physical activity is unclear. Permissive parenting in general has been associated with higher amounts of physical activity among children [21, 22]. Practices related to structure of the environment were also heavily emphasized by parents as practices used to discourage physical activity. The most common practices related to structure involved restriction or rules surrounding outdoor time. There is evidence that outdoor play is declining in North America $[23,24]$. Active outdoor play is important for healthy development of children and parents should encourage their children to explore their environment [25].

There were no significant differences in the reporting of parenting practices used to encourage or discourage physical activity by domain and each of the four sociodemographic variables tested (country, parental sex, age of child, and income).The results are in contrast with studies that have found differences in parenting practices by parental sex [26] and income [11]; however, these studies were conducted in countries other than Canada and the US. Lack of differences in our results among these four socio-demographic variables suggests that the findings of this study may be generalizable to the larger Canada and US population.

This study is not without limitations. The web-based platform used to collect parent responses only allowed for structured questions. Therefore, there was no opportunity to ask parents to elaborate on specific responses or to probe further the meaning of their responses. Further discussions with parents may have uncovered more parenting practices used to encourage or discourage physical activity. In addition, the participants for this study were sampled from a web-based panel and may not be representative of US and Canadian parents. However, a quota sampling approach was used to ensure an income and ethnic distribution that matched the income and ethnic distribution of the US and Canadian population. Furthermore, information about the child's sex was not collected; therefore, we could not examine differences in parenting practices by child sex. Finally, child physical activity behavior was not measured; therefore, the extent to which specific parenting practices influence child behavior cannot be ascertained from this study.

\section{Conclusions}

This study explored common parenting practices used by US and Canadian parents to encourage or discourage physical activity among their children. Parents most often encouraged physical activity through structure and emotional support and discouraged physical activity through lack of structure and control. The findings provide a unique understanding of the approaches used by parents to influence their child's physical activity and highlight the importance of using qualitative methods to uncover parental beliefs and behaviors. Understanding the different behaviors used by parents to influence physical activity will help in the development of an instrument to measure parenting practices related to physical activity. Future studies are needed to ascertain whether these practices used by parents affect child physical activity behavior.

\section{Additional file}

Additional file 1: Appendix 1. Coded responses to parenting practices that encourage physical activity. Appendix 2. Coded responses to parenting practices that discourage physical activity. (DOCX 26 kb)

\section{Acknowledgements}

Not applicable.

\section{Funding}

The project described was supported by the Canadian Institute of Health Research Institute of Nutrition, Metabolism and Diabetes (CIHR-INMD:MOP_ 119359); AT received post-doctoral support from the Child \& Family Research Institute (CFRI) and the Michael Smith Foundation for Health Research; LCM received salary support from BC Children's Hospital Research Institute. The work is also a publication of the US Department of Agriculture (USDA/ARS) Children's Nutrition Research Center, Department of Pediatrics, BCM funded in part by the USDA/ARS (Cooperative Agreement 6250-51,000).

\section{Availability of data and materials}

Please contact corresponding author for data requests.

\section{Authors' contributions}

LCM, TMO, SOH, MRB and TB designed the study. LCM oversaw the data collection. TMO, LCM, AWT were involved in the coding of responses. AWT performed the statistical analyses and drafted the manuscript. All authors provided input to the manuscript and approved the final draft.

Ethics approval and consent to participate

The protocol was approved by the Institutional Review Boards at the University of British Columbia and Baylor College of Medicine.

Consent for publication

Not applicable.

Competing interests

The authors declare that they have no competing interests.

\section{Publisher's Note}

Springer Nature remains neutral with regard to jurisdictional claims in published maps and institutional affiliations.

\section{Author details}

${ }^{1}$ Child \& Family Research Institute, School of Population and Public Health, University of British Columbia, Vancouver, BC, Canada. ${ }^{2}$ USDA/ARS Children's Nutrition Research Center, Baylor College of Medicine, Houston, TX, USA.

${ }^{3}$ School of Kinesiology, University of British Columbia, Vancouver, BC, Canada.

Received: 2 August 2017 Accepted: 15 November 2017

Published online: 01 December 2017

\section{References}

1. Janssen I, Leblanc AG. Systematic review of the health benefits of physical activity and fitness in school-aged children and youth. Int J Behav Nutr Phys Act. 2010;7:40 
2. Colley RC, Garriguet D, Janssen I, et al. Physical activity of Canadian children and youth: accelerometer results from the 2007 to 2009 Canadian health measures survey. Health Rep. 2011;22:15-23.

3. Troiano RP, Berrigan D, Dodd KW, et al. Physical activity in the United States measured by accelerometer. Med Sci Sports Exerc. 2008;40:181-8.

4. Gustafson SL, Rhodes RE. Parental correlates of physical activity in children and early adolescents. Sport Med. 2006;36:79-97.

5. Sleddens EFC, Gerards SMPL, Thijs C, et al. General parenting, childhood overweight and obesity-inducing behaviors: a review. Int J Pediatr Obes. 2011;6:e12-27.

6. Masse LC, O'Connor TM, Tu AW, et al. Are the physical activity parenting practices reported by US and Canadian parents captured in currently published instruments? J Phys Act Health. 2016;13:1070-8.

7. Trost S, Loprinzi P. Parental influences on physical activity behavior in children and adolescents: a brief review. Am J Lifestyle Med. 2011:5:171-81.

8. Beets MW, Cardinal BJ, Alderman BL. Parental social support and the physical activity-related behaviors of youth: a review. Health Educ Behav. 2010;37:621-44.

9. Sleddens EFC, Kremers SPJ, Hughes SO, et al. Physical activity parenting: a systematic review of questionnaires and their associations with child activity levels. Obes Rev. 2012:13:1015-33.

10. Bauer KW, Nelson MC, Boutelle KN, et al. Parental influences on adolescents' physical activity and sedentary behavior: longitudinal findings from project EAT-II. Int J Behav Nutr Phys Act. 2008;5:12.

11. Suen Y, Cerin E, Wu S. Parental practices encouraging and discouraging physical activity in Hong Kong Chinese preschoolers. J Phys Act Health. 2015;12:361-9.

12. O'Connor TM, Cerin E, Hughes SO, et al. What Hispanic parents do to encourage and discourage 3-5 year old children to be active: a qualitative study using nominal group technique. Int I Behav Nutr Phys Act. 2013;10:93.

13. Hardy LL, Hector D, Saleh S, et al. Australian middle eastern parents' perceptions and practices of children's weight-related behaviours: talking with parents' study. Health Soc Care Community. 2016;24:e63-71.

14. Willis GB. Gordon B. Cognitive interviewing : a tool for improving questionnaire design. Thousand Oaks: Sage Publications; 2005.

15. Davison KK, Mâsse LC, Timperio A, et al. Physical activity parenting measurement and research: challenges, explanations, and solutions. Child Obes. 2013:9:S103-9.

16. Vaughn AE, Ward DS, Fisher JO, et al. Fundamental constructs in food parenting practices: a content map to guide future research. Nutr Rev. 2016; 74:98-117.

17. Cleland V, Timperio A, Salmon J, et al. A longitudinal study of the family physical activity environment and physical activity among youth. Am J Health Promot. 2011;25:159-67.

18. Jago R, Fox KR, Page AS, et al. Parent and child physical activity and sedentary time: do active parents foster active children? BMC Public Health. 2010;10:194.

19. Verloigne M, Van Lippevelde W, Maes L, et al. Family- and school-based correlates of energy balance-related behaviours in 10-12-year-old children: a systematic review within the ENERGY (EuropeaN Energy balance research to prevent excessive weight gain among youth) project. Public Health Nutr. 2012;15:1380-95

20. Jago R, Davison KK, Thompson JL, et al. Parental sedentary restriction, maternal parenting style, and television viewing among 10- to 11-year-olds. Pediatrics. 2011:128:e572-8.

21. Jago R, Davison KK, Brockman R, et al. Parenting styles, parenting practices, and physical activity in 10- to 11-year olds. Prev Med (Baltim). 2011;52:44-7.

22. Salmon J, Timperio A, Telford A, et al. Association of Family Environment with Children's television viewing and with low level of physical activity. Obes Res. 2005;13:1939-51.

23. Bassett $D R$, John $D$, Conger $S A$, et al. Trends in physical activity and sedentary Behaviors of United States youth. J Phys Act Health. 2015;12: 1102-11.

24. Active Healthy Kids Canada. Is active play extinct? Report card on the physical activity of children and youth. Toronto: Active Healthy Kids Canada; 2012.

25. Tremblay MS, Gray C, Babcock S, et al. Position statement on active outdoor play. Int J Environ Res Public Health. 2015;12:6475-505.

26. Lloyd AB, Lubans DR, Plotnikoff RC, et al. Maternal and paternal parenting practices and their influence on children's adiposity, screen-time, diet and physical activity. Appetite. 2014;79:149-57.

\section{Submit your next manuscript to BioMed Central and we will help you at every step:}

- We accept pre-submission inquiries

- Our selector tool helps you to find the most relevant journal

- We provide round the clock customer support

- Convenient online submission

- Thorough peer review

- Inclusion in PubMed and all major indexing services

- Maximum visibility for your research

Submit your manuscript at www.biomedcentral.com/submit
Biomed Central 